\title{
Effect of Flow Diverter Porosity on Intraaneurysmal Blood Flow
}

\author{
Luca Augsburger1,2, Mohamed Farhat ${ }^{3}$, Philippe Reymond', Edouard Fonck ${ }^{1,2}$, Zsolt Kulcsar², \\ Nikos Stergiopulos ${ }^{1}$, Daniel A. Rüfenacht ${ }^{2}$
}

\begin{abstract}
Background and Purpose: Growth and rupture, the two events that dominate the evolution of an intracranial aneurysm, are both dependent on intraaneurysmal flow. Decrease of intraaneurysmal flow is considered an attractive alternative for treating intracranial aneurysms by minimally invasive techniques. Such modification can be achieved by inserting stents or flow diverters alone. In the present paper, the effect of different commercial and innovative flow diverters' porosity was studied in intracranial aneurysm models.

Material and Methods: Single and stent-in-stent combination of Neuroform II as well as single and stent-in-stent combination of a new innovative, low-porosity, intracranial stent device (D1, D2, D1 + D2) were inserted in models of intracranial aneurysms under shear-driven flow and inertia-driven flow configurations. Steady and pulsating flow rates were applied using a blood-like fluid. Particle image velocimetry was used to measure velocity vector fields in the aneurysm midplane along the vessel axis. Flow and vorticity patterns, velocity and vorticity magnitudes were quantified and their value compared with the same flows in absence of the flow diverter.

Results: In absence of flow diverters, a solid-like rotation could be observed in both shear-driven and inertia-driven models under steady and pulsatile flow conditions. The flow effects due to the insertion of low-porous devices such as D1 or D2 provoked a complete alteration of the flow patterns and massive reduction of velocity or vorticity magnitudes, whereas the introduction of clinically adopted high-porous devices provoked less effect in the aneurysm cavity. As expected, results showed that the lower the porosity the larger the reduction in velocity and vorticity within the aneurysm cavity. The lowest-porosity device combination (D1 and D2) reached an averaged reduction of flow parameters of $80 \%$ and $88 \%$ under steady and pulsatile flow conditions, respectively. The reduction in mean velocity and vorticity was much more significant in the shear-driven flows as compared to the inertia-driven flows.

Conclusion: Although device porosity is the main parameter influencing flow reduction, other parameters such as device design and local flow conditions may influence the level of flow reduction within intracranial aneurysms.
\end{abstract}

Key Words: Intracranial aneurysms · Particle image velocimetry · Porosity · Experimental setup · Shear-driven flow $\cdot$ Inertia-driven flow

Clin Neuroradiol 2009;19:204-14

DOI 10.1007/s00062-009-9005-0

\section{Effekt der Porosität von „flow diverters“ auf den intraaneurysmatischen Blutfluss}

Hintergrund und Ziel: Die zwei wichtigsten Faktoren für die Entwicklung intrazerebraler Aneurysmen, nämlich Wachstum und Ruptur, hängen vom intraaneurysmatischen Blutfluss ab. Eine Verminderung des intraaneurysmatischen Blutflusses durch minimalinvasive Techniken wird als attraktive Behandlungsmethode erachtet. Eine solche Modifikation des Blutflusses kann durch das Einbringen eines Stents oder "flow diverter" allein erzielt werden. In der vorliegenden Arbeit untersuchten die Autoren den Effekt der Porosität verschiedener handelsüblicher und innovativer "flow diverters" an Modellen intrakranieller Aneurysmen.

Material und Methodik: Sowohl einzelne oder Stent-in-Stent-Kombinationen des Neuroform II (NF) als auch einzelne oder Stent-in-Stent-Kombinationen von neuen innovativen, niedrigporösen intrakraniellen Stents (D1, D2, D1 + D2) wur-

\footnotetext{
${ }^{1}$ Laboratory of Hemodynamics and Cardiovascular Technology, École Polytechnique Fédérale

de Lausanne, Switzerland,

${ }^{2}$ Neuro-Interventional Service, Clinical Neurosciences Department, University Hospital of

Geneva, Switzerland,

${ }^{3}$ Hydraulic Machines Laboratory, École Polytechnique Fédérale de Lausanne, Switzerland.

Received: March 12, 2009; revision accepted: June 17, 2009

Published Online: August 23, 2009
} 
den in Modellen intrakranieller Aneurysmen mit Eigenschaften von "shear-driven" und "inertia-driven" Fluss platziert. Flächen mit Geschwindigkeitsvektoren in der mittleren Ebene des Aneurysmas parallel zur Achse des Gefäßes wurden mit Hilfe der "particle image velocimetry“ (PIV) ermittelt. Eigenschaften von Fluss und Verwirbelungen, Geschwindigkeit und Ausmaß von Verwirbelungen wurden gemessen und mit Messwerten des gleichen Modells ohne "flow diverter" verglichen. Ergebnisse: Ohne "flow diverter" konnte eine beständige Rotation in beiden - "shear-driven“ und „inertia-driven" - Flussmodellen beobachtet werden. Die Auswirkungen nach Platzierung eines niedrigporösen Modells wie D1 oder D2 riefen eine komplette Änderung der Flusseigenschaften und eine massive Verringerung der Geschwindigkeit und des Ausmaßes von Verwirbelungen hervor, wohingegen die Platzierung klinisch angewendeter hochporöser Modelle geringere Auswirkungen auf die Kavität des Aneurysmas hatte. Erwartungsgemäß haben die Ergebnisse gezeigt: Je kleiner die Porosität ist, desto größer sind die Auswirkungen auf Blutflussgeschwindigkeit und Verwirbelungen im Aneurysma. Die Kombination mit der geringsten Porosität (D1 und D2) erzielte eine durchschnittliche Reduktion der Flussparameter um $80 \%$ bzw. $88 \%$ bei konstanten und pulsatilen Flüssen. Die Verminderung von mittlerer Geschwindigkeit und von Verwirbelungen war beim "shear-driven“ Fluss deutlich signifikanter als beim „inertia-driven“ Fluss.

Schlussfolgerung: Obwohl die Porosität der wichtigste Parameter zur Senkung des Flusses ist, können andere Parameter wie das Design des jeweiligen Modells oder lokale Flusseigenschaften die Wirksamkeit der Flussreduktion in intrakraniellen Aneurysmen beeinflussen.

Schlüsselwörter: Intrakranielle Aneurysmen · Particle image velocimetry · Porosität · Experimenteller Aufbau • Shear-driven flow $\cdot$ Inertia-driven flow

\section{Introduction}

Treatment of intracranial aneurysms aims at disconnecting the aneurysmal flow from the parent artery and at restoring a physiological flow. Such treatment can be performed through neurosurgery by placing a metallic clip around the aneurysmal neck disconnecting in a definitive manner the aneurysmal flow from the parent artery flow. However, these approaches have high complication risks, such as brain edema or arterial vasospasm [1]. Minimally invasive treatments provide better results [2] and are accomplished by filling the aneurysm cavity with coils and, in certain cases, by deploying an intracranial stent which is aiming at maintaining the coils compacted and at redirecting the flow in the parent artery. With flow currently thought to be the key parameter that can be influenced by minimally invasive treatments immediately, self-expanding and specifically designed stents for the cerebral vasculature have been used in patients for treatment of cerebral aneurysms [3]. It is believed that stents or flow diverters alone will be able to redirect the flow in the parent artery and slow down the aneurysmal flow leading to a thrombus, thus stabilizing the aneurysm in a definitive manner. Some authors have also reported a stent-in-stent technique to increase the lateral hemodynamic resistance of the stent in dissecting or small wide-necked aneurysms [4-7]. New generation of intracranial stents and recent devices called flow diverters are thought to progressively become the current optimal minimally invasive treatment for intracranial aneurysms $[8,9]$. Such devices have a lower porosity and are used for stand-alone treatment.
Previous open-cell design stents were mostly used to maintain the coils compacted inside the aneurysm cavity and had only a limited effect on aneurysmal flow. Preliminary clinical experiences with stent-based flow diversion have been reported where progressive aneurysmal thrombosis induced by single or double stenting was observed for wide-necked aneurysms and complex vertebrobasilar aneurysms $[5-7,10]$.

Earlier studies have shown that the efficacy of a flow diverter to reduce flow within the aneurysmal sac depends on its porosity [11] and on the local hemodynamic conditions [12].

The first goal of our study is to quantify the effect of intracranial stent porosity on intraaneurysmal flow characteristics using two different devices with distinct porosities and their stent-in-stent combinations to further reduce porosity. The second goal is to examine the efficacy of intracranial stents in reducing intraaneurysmal flow under two different flow conditions.

\section{Material and Methods}

\section{Experimental Setup}

A hydraulic circuit (Figure 1a) was designed and set up to investigate the steady and pulsatile flow in two silicone models of cerebral aneurysms. It consisted of a programmable pulsating flow pump, a reservoir, a pressure sensor, a flowmeter, upstream and downstream pipes, gates and the test section made out of a box containing the immersed silicone cerebral aneurysm models. This setup was placed on a breadboard on an optical table and was designed to minimize hy- 
a

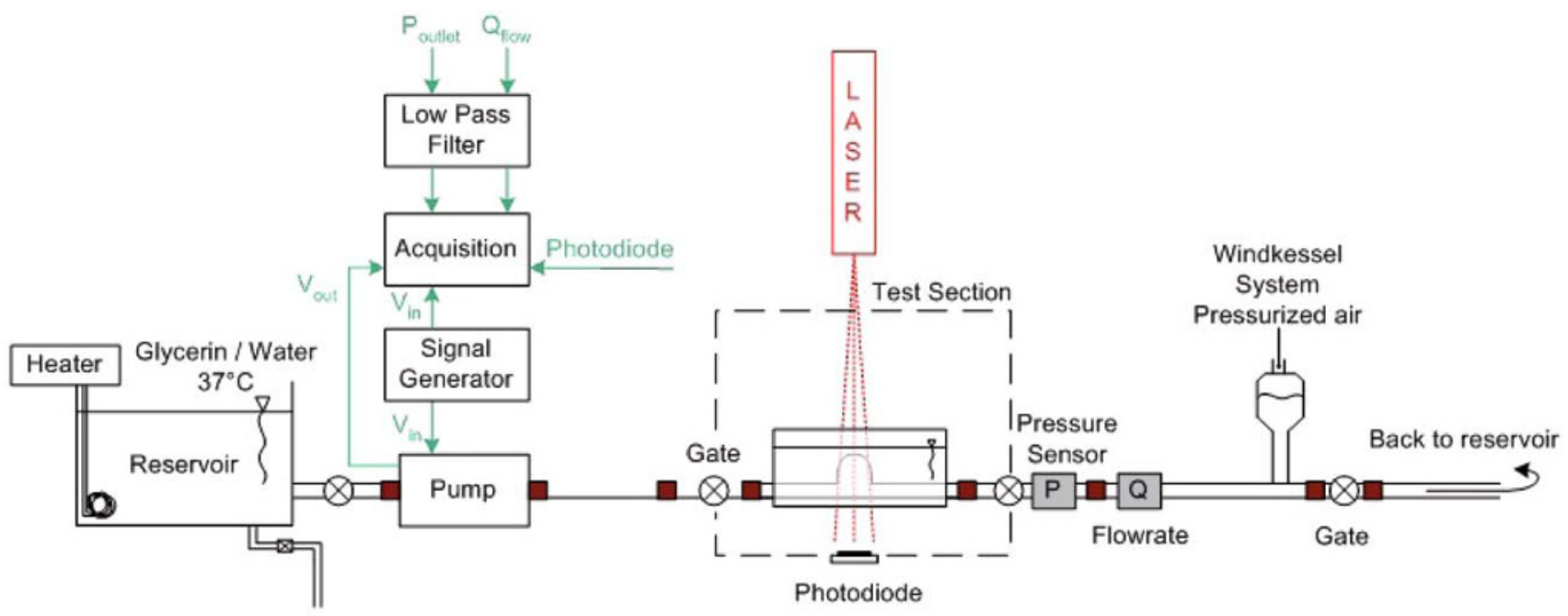

b

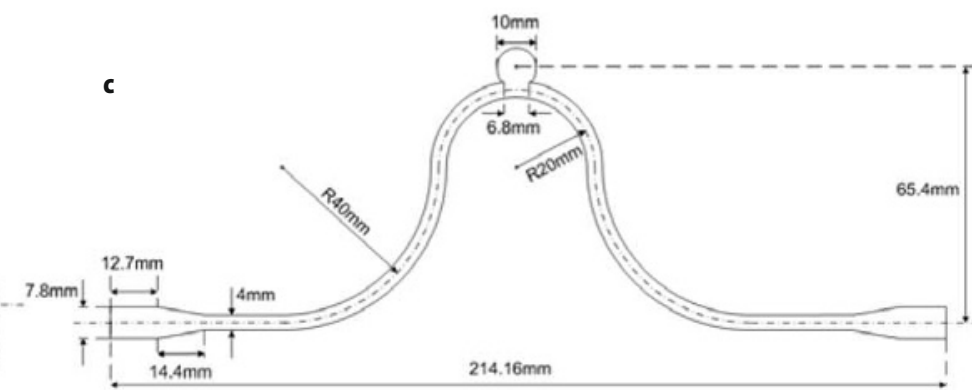

Figures 1a to 1c. Schematics of the circulation system (a), and of the silicone models (b, c).

draulic perturbations. All pipe diameters were in the range of cerebral artery diameters and were stiff. In addition, no major diameter changes and curves were allowed.

A gear pump (ISMATEC, MCP-Z Process, Glattbrugg, Switzerland) drove the flow and was controlled by a function generator which was programmed to reproduce physiologically relevant flow waveforms similar to those found in a cerebral artery. A 7-1 covered reservoir at atmospheric pressure was placed close to the pump. Pulsating pressure at the outlet of the test section was monitored using a miniature pressure sensor (Unisensor, Rickenbach-Attikon, Switzerland) and a standard oscilloscope (LeCroy, Chestnut, NY, USA). Flow was monitored using an ultrasonic flowmeter device (T-102, Transonic Systems Europe, Maastricht, The Netherlands), also placed downstream of the test section. To yield blood-like viscosity of 3.75 $\mathrm{mPa} \cdot s$ at body temperature, fluid was composed of a mixture of distilled water and 50.2\% glycerin (Pharma
$86.5 \%$, Reactolab SA, Servion, Switzerland). The fluid temperature was maintained at $37^{\circ} \mathrm{C}$ using a thermostat.

\section{Silicone Models}

Two four-layer silicone models (ELASTRAT SàRL, Geneva, Switzerland) were used (Figures 1b and 1c).

The choice of the models was done in order to allow for the investigation of two different kinds of aneurysmal flows. Indeed, for a given aneurysm geometry, straight and curved parent vessels provide differences in the potential occlusion created by a specific stent [12]. The first model used consisted of a lateral aneurysm placed over a straight parent artery. This geometry drove a shear-driven flow, i.e., the aneurysmal flow was "induced" by the arterial flow. The second model used consisted of a similar lateral aneurysm geometry placed over a curved parent artery exhibiting consequently an inertia-driven flow, meaning that the arterial flow was pointing inside the aneurysmal sac. The aneurysm models had a spherical shape 
Table 1. Porosity values for each device or combination of devices tested.

\begin{tabular}{lc}
\hline Device of combination & Porosity \\
\hline (a) No device & $100 \%$ \\
(b) Neuroform & $87 \%$ \\
(c) Two Neuroform & $74 \%$ \\
(d) Low-porous device (D1) & $63 \%$ \\
(e) Low-porous device (D2) & $63 \%$ \\
(f) Combination of D1 and D2 & $45 \%$ \\
\hline
\end{tabular}

with a $10-\mathrm{mm}$ diameter and an elliptic neck with a 6.8 -mm major axis and a 3.5-mm minor axis. The parent artery had a 4-mm diameter. The vessel orientation was horizontal with the aneurysm cavity on top of the vessel. In order to avoid major optical deformation due to the aneurysm curvature, the models were further immersed in a Plexiglas box filled with the same fluid as the flowing fluid. Indeed, silicone and the fluid used in this experiment have similar refraction indexes: $\mathrm{n}_{\text {silicone }}=1.42$ and $\mathrm{n}_{\text {fluid }}=1.47$, respectively. This assumption was confirmed experimentally using an optical target.

\section{Flow Diverters Tested}

All tested devices were self-expanding flow diverters and made of nitinol. The first group of devices has an open-cell design and exhibits a relatively large porosity whereas the second group of devices presents an asymmetric design and made of three supporting helicoidal wires. Smaller connection wires join the principal spires and are spaced at the device edges and brought closer in the device center. Due to patent issues, the device cannot be illustrated. The effective porosity defined as the ratio of the free neck surface divided by the total neck area (equation 1) could be approximated and the corresponding values of the tested devices are summarized in Table 1 . Three flow diverters and six device combinations were tested: (a) no stent, (b) one Neuroform II (Boston Scientific, Boston, MA, USA), (c) a stent-in-stent combination of two Neuroform II, (d) a low-porous device (D1), (e) a second low-porous device (D2), and (f) the stent-in-stent combination of D1 and D2.

Effective porosity $=\frac{A_{\text {free }}}{A_{\text {total }}}=\frac{A_{\text {total }}-A_{\text {device }}}{A_{\text {total }}}=1-\frac{A_{\text {device }}}{A_{\text {total }}}$

\section{Velocity Field Measurement}

Particle image velocimetry (PIV) is based on the comparison of particles' position in a succession of flow field images separated by a controlled interval of time. Once
Table 2. Steady and pulsatile flow condition parameters.

\begin{tabular}{lrrrl}
\hline Parameters & \multicolumn{2}{l}{ Steady flow } & & Pulsating flow \\
\hline$Q_{\text {mean }}$ & 100 & 300 & 500 & 333 \\
$V_{\text {mean }}$ & 13.3 & 39.8 & 66.3 & 44.2 \\
Re & 141 & 423 & 705 & 461 \\
$\alpha$ & 0 & 0 & 0 & 2.59 \\
Pulsatility index & 0 & 0 & 0 & 0.65 \\
\hline
\end{tabular}

the image acquisition is done, an algorithm analyzes and correlates a pair of images to extract the velocity vector fields. In the present setup, particles of a size equivalent to red blood cells $(\sim 10 \mu \mathrm{m})$ having a density close to water density were illuminated using a double-pulsed laser sheet (DANTEC New Wave Research solo PIV III 15Hz, Dantec Dynamics S.A.S., Nozay, France). The digital camera had a resolution of $1,280 \times 1,024$ pixels (Camera DANTEC Measuring Technology HiSense PIV/PLIF Camera). The velocity vectors were averaged over 80 sets of double images at 4-Hz sampling frequency. For measurements under pulsatile flow conditions, phase averaging was performed at each time step within the pulsation cycle with the help of a delayed trigger signal for laser activation and image acquisition. Hence, the instantaneous measurement was always taken at the same time of the cardiac cycle. A photodiode sensor, placed beneath the model, was used to monitor the exact timing of laser pulses. The procedure was repeated to obtain 20 points on one cardiac cycle, i.e., each $50 \mathrm{~ms}$. The time interval between the two laser pulses was set in such a way that the fastest particle travels no more than half of the interrogation window length. The background noise was first filtered by subtracting the average image from PIV images before the calculation of cross correlation. Diverse filters were then applied to instantaneous velocity maps to eliminate wrong vectors. Finally, the velocity maps were averaged and the vorticity field was derived.

\section{Flow Conditions}

PIV measurements were performed in the transectional plane of the aneurysm cavity before and after insertion of the tested devices under various flow conditions. The different steady and pulsating flow conditions are detailed in Table 2. $\mathrm{Q}_{\text {mean }}$ is the mean flow rate given in milliliters per minute $(\mathrm{ml} / \mathrm{min}) ; \mathrm{V}_{\text {mean }}$ is the mean velocity in centimeters per second $(\mathrm{cm} / \mathrm{s})$. The Reynolds number, Re, is a dimensionless number representing the ratio of inertial 


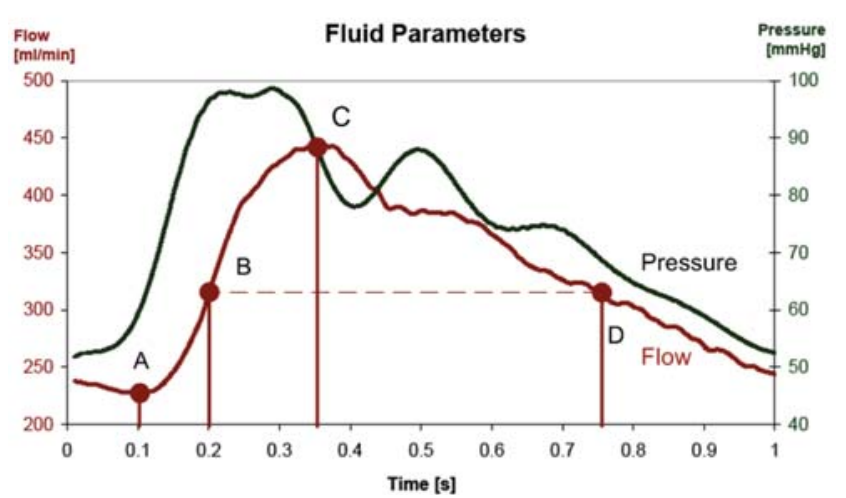

Figure 2. Flow and pressure phase average over time at the outlet of the test section. Illustration of the four main phases evaluated in the cycle: point $A$ : diastolic flow $(t=0.10 \mathrm{~s})$; point $B$ : mid-systolic flow $(t=0.20 \mathrm{~s})$; point $C$ : peak systolic flow $(t=0.35 \mathrm{~s})$; point $D$ : corresponding B-point flow in diastole $(t=0.75 \mathrm{~s})$.

forces to viscous forces and is given by: $\mathrm{Re}=\varrho V_{\text {mean }} D \mu^{-1}$, where $\varrho$ is the density in $\mathrm{kg} \cdot \mathrm{m}^{-3}, D$ is the parent artery diameter, and $\mu$ is the fluid dynamic viscosity in $\mathrm{Nsm}^{-2}$. The Womersley number, $\alpha$, is a dimensionless number which expresses the pulsating flow frequency in relation to viscous effects; it is defined by $\alpha=r\left(\omega \varrho \mu^{-1}\right)^{0.5}$, where $\mathrm{r}$ is the parent artery radius in $m$, and $\omega$ the angular frequency in $\mathrm{rad} \cdot \mathrm{s}^{-1}$. Finally, the pulsatility index is given by $\frac{V_{\max }-V_{\min }}{V_{\operatorname{man}}}$, where $V_{\max }$ and $V_{\min }$ are the maximal and minimal flow velocity during the cardiac cycle, respectively.
The flow and pressure phase average at the outlet of the test section is illustrated in Figure 2.

\section{Analysis}

For each tested device (no device, one Neuroform, two Neuroform, one D1, one D2, D1 and D2) and flow condition (steady and pulsating), the velocity vector fields in the symmetry plane of the aneurysm model were measured. In order to assess the efficiency of the inserted flow diverter, the following parameters were estimated and compared:

(1) the average aneurysm velocity, given by $V_{\text {mean }}=\frac{1}{n} \sum_{i=1}^{i=n}\left\|_{i}\right\|$ expressed in $m s^{-1}$, where $\mathrm{n}$ is the number of valid vectors in the measurement plane and $\mathrm{v}_{\mathrm{i}}$ the velocity vector i at point $\langle\mathrm{u}$; $\mathrm{v}\rangle$;

(2) the root mean square (RMS) value of the vorticity magnitude given by $\omega_{\text {mean }}=\frac{1}{n} \sum_{i=1}^{i=n}\left(\omega_{i}^{2}\right)^{0.5}$, expressed in $\mathrm{rad} \cdot \mathrm{s}^{-1}$, where $\mathrm{n}$ is the number of valid vectors in the measurement plane, and $\omega_{\mathrm{i}}$ the vorticity value at point $\langle\mathrm{u}$; v $\rangle$.

\section{Results}

\section{Qualitative Flow Field Analysis: Effect of Decreasing Porosity on Velocity Vector Fields}

Figures 3 to 5 illustrate the velocity vector fields, the velocity and vorticity magnitudes, respectively, at the peak systolic and diastolic flow times in the shear-driven flow and inertia-driven flow model.

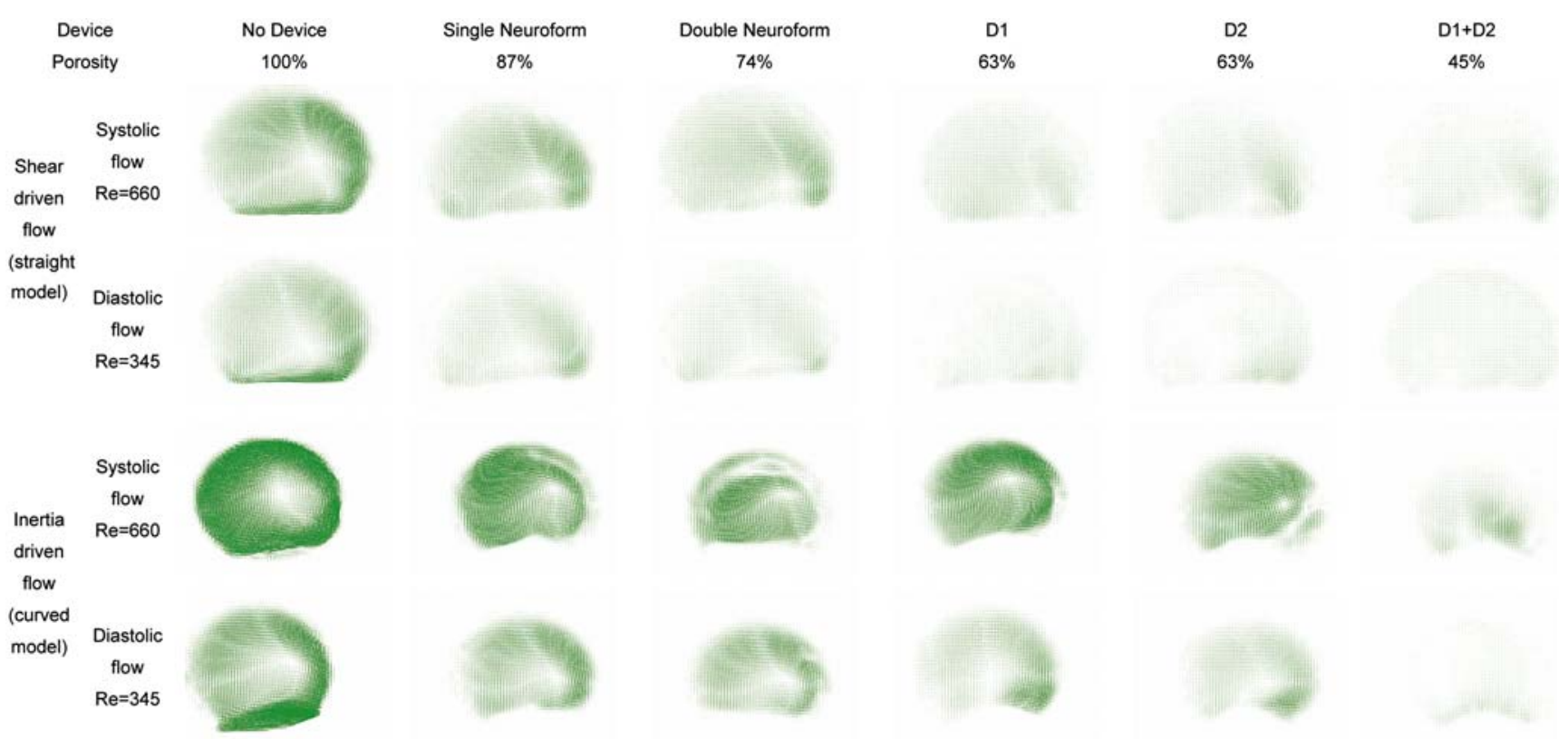

Figure 3. Velocity vector field at peak systole and diastole under shear-driven and inertia-driven flow. 


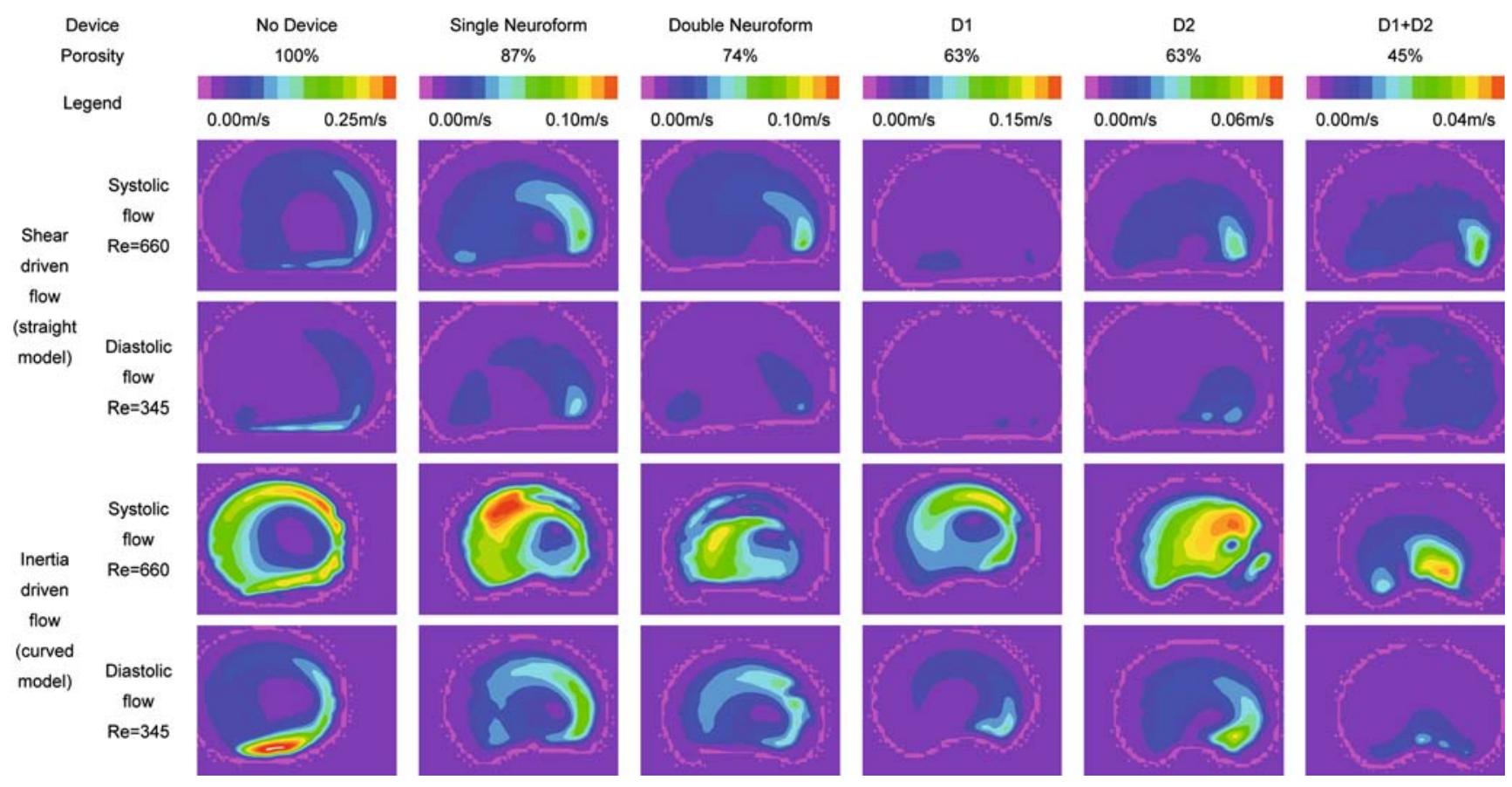

Figure 4. Scalar map of the velocity field at peak systole and diastole under shear-driven and inertia-driven flow.

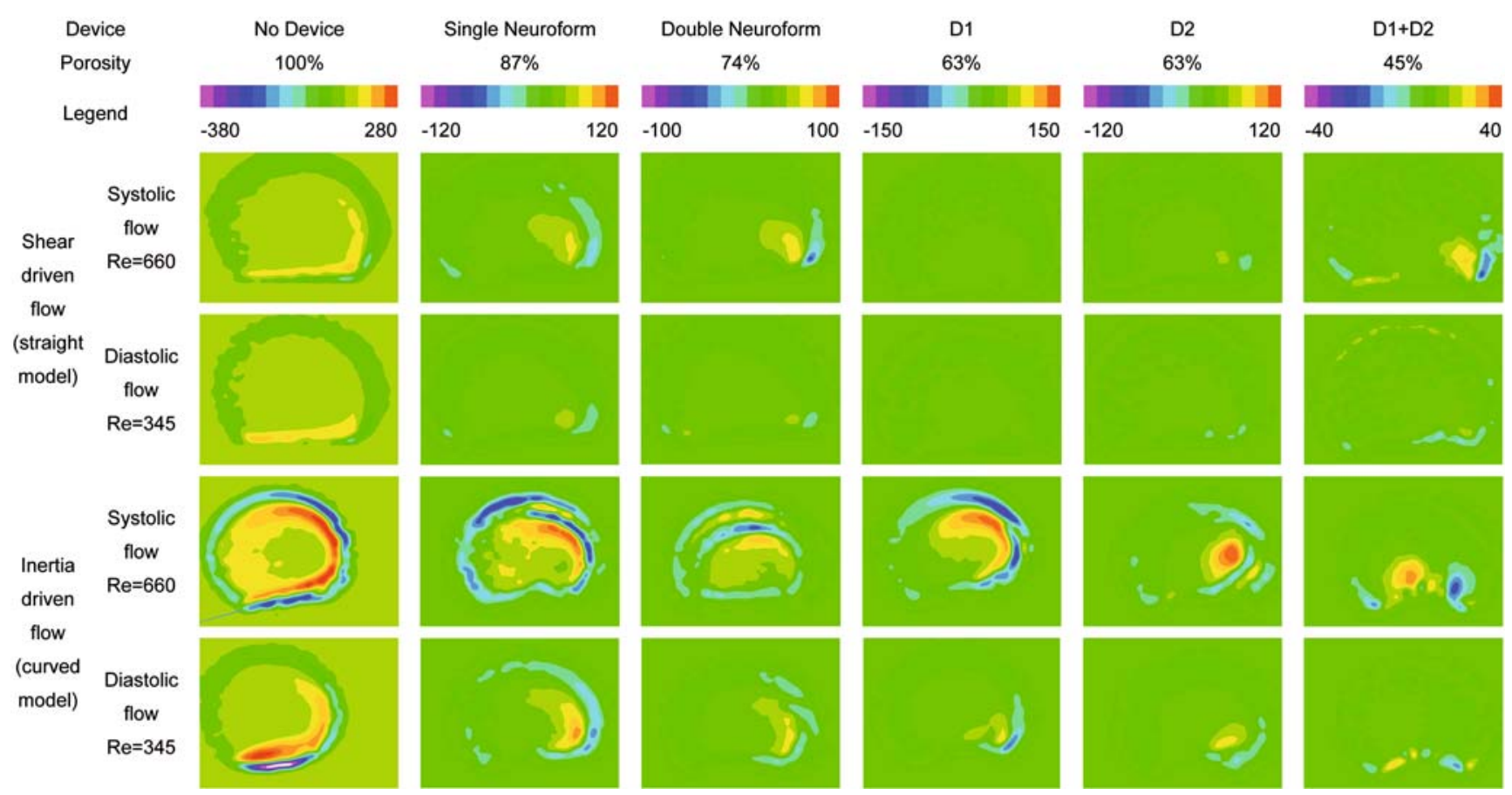

Figure 5. Scalar map of the vorticity field at peak systole and diastole and under shear-driven and inertia-driven flow conditions. Velocity values are expressed in $\mathrm{ms}^{-1}$ and vorticity in $\mathrm{s}^{-1}$.

\section{Quantitative Flow Field Analysis}

Table 3 gives the values of mean aneurysmal velocity and RMS of vorticity for the shear-driven and inertia-driven flow under steady and pulsating flow condi- tions. The numbers in parentheses give the ratio (expressed as percentage) of the measured quantity in presence of a flow-diverting device to the same quantity in absence of device. 
Table 3. Mean aneurysmal velocity, root mean square (RMS) vorticity values and in parentheses their corresponding remaining values expressed in percent for the combination of the different endovascular devices placed in the shear-driven flow and inertia-driven flow models under steady and pulsating flow. NF: Neuroform.

\begin{tabular}{|c|c|c|c|c|c|c|c|}
\hline \multirow[t]{2}{*}{ Device } & \multirow[t]{2}{*}{ Porosity } & \multirow{2}{*}{$\begin{array}{l}\text { Steady/ } \\
\text { pulsatile }\end{array}$} & \multirow{2}{*}{$\begin{array}{l}\text { Mean } \\
\text { flow }\end{array}$} & \multicolumn{2}{|c|}{ Shear-driven flow (straight model) } & \multicolumn{2}{|c|}{ Inertia-driven flow (curved model) } \\
\hline & & & & $\begin{array}{l}\text { Mean velocity } \\
* 1 \mathrm{E}-03\end{array}$ & RMS vorticity & $\begin{array}{l}\text { Mean velocity } \\
* 1 \mathrm{E}-03\end{array}$ & RMS vorticity \\
\hline \multirow[t]{4}{*}{$\mathrm{D} 1+\mathrm{D} 2$} & $45 \%$ & Steady & 500 & $3.29(19 \%)$ & $3.03(17 \%)$ & $21.7(31 \%)$ & $23.7(19 \%)$ \\
\hline & & & 300 & $1.87(14 \%)$ & $1.87(14 \%)$ & $2.00(6 \%)$ & $1.58(5 \%)$ \\
\hline & & & 100 & $0.91(15 \%)$ & $0.62(9 \%)$ & $0.34 \quad(3 \%)$ & $0.26 \quad(2 \%)$ \\
\hline & & Pulsatile & 333 & $2.30(14 \%)$ & $1.48(10 \%)$ & $2.45(5 \%)$ & $1.81(3 \%)$ \\
\hline \multirow[t]{4}{*}{ D1 } & $63 \%$ & Steady & 500 & $3.77(21 \%)$ & $2.85(16 \%)$ & $32.0(46 \%)$ & $30.8(37 \%)$ \\
\hline & & & 300 & $2.04(15 \%)$ & $1.31(10 \%)$ & $16.0(46 \%)$ & $14.7(45 \%)$ \\
\hline & & & 100 & $1.17(20 \%)$ & $0.71(11 \%)$ & $1.31(11 \%)$ & $1.04(8 \%)$ \\
\hline & & Pulsatile & 333 & $3.19(20 \%)$ & $2.07(14 \%)$ & $16.5(35 \%)$ & $15.2(28 \%)$ \\
\hline \multirow[t]{4}{*}{ D2 } & $63 \%$ & Steady & 500 & $4.05(23 \%)$ & $3.14(18 \%)$ & $28.7(42 \%)$ & $25.1(30 \%)$ \\
\hline & & & 300 & $3.71(28 \%)$ & $2.94(22 \%)$ & $7.06(20 \%)$ & $5.45(17 \%)$ \\
\hline & & & 100 & $0.87(14 \%)$ & $0.62 \quad(9 \%)$ & $0.92 \quad(8 \%)$ & $0.55 \quad(4 \%)$ \\
\hline & & Pulsatile & 333 & $3.54(22 \%)$ & $2.28(16 \%)$ & $10.2(22 \%)$ & $8.02(15 \%)$ \\
\hline \multirow[t]{4}{*}{$2 \mathrm{NF}$} & $74 \%$ & Steady & 500 & $6.13(35 \%)$ & $4.44(25 \%)$ & $34.9(51 \%)$ & $33.9(41 \%)$ \\
\hline & & & 300 & $4.72(36 \%)$ & $3.30(24 \%)$ & $21.1(61 \%)$ & $21.2(65 \%)$ \\
\hline & & & 100 & $3.25(54 \%)$ & $1.64(24 \%)$ & $19.4(56 \%)$ & $18.6(57 \%)$ \\
\hline & & Pulsatile & 333 & $6.10(38 \%)$ & $3.90(26 \%)$ & $15.2(26 \%)$ & $13.6(19 \%)$ \\
\hline \multirow[t]{4}{*}{ NF } & $87 \%$ & Steady & 500 & $9.29(52 \%)$ & $7.31(41 \%)$ & $42.1(61 \%)$ & $43.6(53 \%)$ \\
\hline & & & 300 & $5.88(44 \%)$ & $4.11(30 \%)$ & $22.1(64 \%)$ & $21.4(66 \%)$ \\
\hline & & & 100 & $1.35(23 \%)$ & $1.34(20 \%)$ & $3.61(31 \%)$ & $2.87(22 \%)$ \\
\hline & & Pulsatile & 333 & $7.44(47 \%)$ & $5.17(35 \%)$ & $20.0(44 \%)$ & $7.5(34 \%)$ \\
\hline \multirow[t]{4}{*}{ None } & $100 \%$ & Steady & 500 & 17.7 & 17.8 & 68.9 & 82.8 \\
\hline & & & 300 & 13.3 & 13.5 & 34.6 & 2.7 \\
\hline & & & 100 & 6.0 & 6.71 & 11.6 & 13.0 \\
\hline & & Pulsatile & 333 & 15.8 & 14.6 & 45.0 & 52.6 \\
\hline
\end{tabular}

Velocity and vorticity magnitudes were found to be three to four times higher in the inertia-driven flow model than in the shear-driven flow model, with or without the presence of any device. This reflects the well-anticipated fact that when the parent vessel points toward the aneurysm neck, flow enters the aneurysm inflow zone easier and at a higher speed, producing accordingly higher velocity in the aneurysm.

The efficiency of the flow diverter in reducing intraaneurysmal flow is primarily determined by its porosity. This is illustrated in Figure 6, where under pulsating flow conditions an overall monotonic decrease in mean velocity and vorticity is observed with decreased porosity. We remark, however, that although D1 and D2 have the same porosity, their effect on aneurysmal flow is similar in the shear-driven model whereas it is substantially different in the inertia-driven flow model. Indeed, in the inertia-driven flow model, D1 and D2 are exhibiting different mean velocity values: $\mathrm{D} 1=16.5 \mathrm{~mm} / \mathrm{s}$; D2 $=10.2 \mathrm{~mm} / \mathrm{s}$ (difference $38 \%$ ) and different vorticity values: 15.19 versus 8.02 (difference $47 \%$ ). Furthermore, in the inertia-driven flow model, the stent-in-stent combination of two Neuroform (porosity $74 \%$ ) is presenting higher flow reduction efficiency than D1 (porosity $63 \%$ ).

When comparing steady versus pulsating flow (Table 3), we observe that the pulsatile flow conditions do not seem to be a major determinant of the effectiveness of the flow diverter in reducing velocity and vorticity. Flow rate, however, appears to be a considerable modulator of flow reduction efficiency. As seen in Table 3, mean aneurysmal velocity and the vorticity RMS reduction rates are not constant for the different reported steady flow rates and are generally higher for the smallest flow rate $(100 \mathrm{ml} / \mathrm{min})$. 

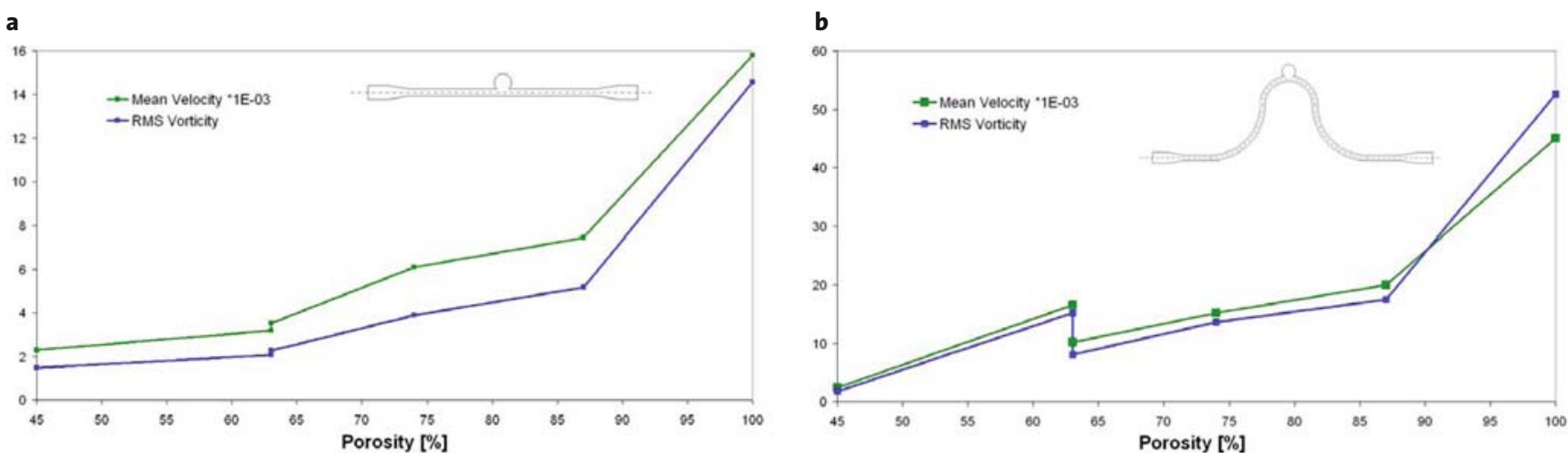

Figures $\mathbf{6 a}$ and $\mathbf{6 b}$. Effect of porosity in the shear-driven model (a) and in the inertia-driven model (b) over the mean velocity and RMS vorticity values.

\section{Discussion}

Summary of the Study

In vitro experiments are used and developed to understand flow diverters' efficiency and consequently facilitate their development. Such setups are reproducing the physiological parameters such as flow and pressure and thus avoid the unnecessary use of animals. Flow patterns, velocities, pressure and their derived quantities such as shear and vorticity are made accessible by direct measurements $[13,14]$. Alterations of these quantities due to the insertion of a stent were quantified in previous studies by Lieber et al. [11], Rhee et al. [15], and Barath et al. [16-18].

PIV is a nonintrusive technique which allows reconstructing the velocity vector fields in a flowing fluid seeded with particles. This technique, which is widely adopted in a variety of liquid and gas flows, has been used by Lieber et al. to quantify the effects of the strut size of three helical stents on flow [19], by Canton et al. to measure the intraaneurysmal flow dynamics' and mechanical stresses' changes resulting from the placement of Neuroform stents in bifurcating intracranial aneurysm models [20], and by $\mathrm{Yu}$ et al. in stented and unstented sidewall aneurysm models under steady flow of different Reynolds numbers [21].

Earlier studies have shown that endovascular flow diverters are capable of reducing intraaneurysmal flow and that porosity is a major determinant of this flow reduction $[11,15]$. The current study aimed in complementing and further extending those studies, by examining and comparing the effects of two versions (D1 and D2) of a novel low-porosity endovascular flow diverter with those from a commercially available device (Neuroform) that is already in use for clinical application.
Stent-in-stent combinations of D1 and D2 and the Neuroform, yielding further reduction in porosity, were also studied. Mean velocity and RMS value of vorticity were measured using PIV on idealized models of shear-driven and inertia-driven intraaneurysmal flows under physiologically relevant steady and pulsating flow conditions. We found that, indeed, porosity is the principal parameter affecting intraaneurysmal flow, but the effects of porosity as well as the absolute levels of intraaneurysmal flow are strongly dependent on the local magnitude and nature of flow, that is whether the local flow is shear-driven or inertia-driven.

Compared to previous studies, the present paper offers the advantage of providing a better spatial resolution (pixel size comprised between $11 \mu \mathrm{m}$ and $18 \mu \mathrm{m}$ ), and a better temporal resolution (a photodiode sensor was placed beneath the model and the exact time of laser hits was monitored with a $200-\mathrm{MHz}$ bandwidth oscilloscope). Secondly, velocity and vorticity magnitudes were evaluated qualitatively and quantitatively, finally, two simple geometries but completely different in a fluid mechanics approach were used providing completely different kind of flow.

\section{Effect of Porosity and Strut Design}

The differences in flow reduction efficiency among the different porosity devices are significant. The lowest-porosity device tested (stent-in-stent combination of D1 and D2) reduced the aneurysmal flow or vorticity at the levels of $14-19 \%$ of control under shear-driven flows and to the levels of $5-31 \%$ under inertia-driven flows. High-porosity Neuroform led to a reduction in mean velocity at the levels of $23-52 \%$ under shear-driven flow and to the levels of $31-61 \%$ under inertia-driven flow. 
The results of the present study agree well with those from a previous study using the Neuroform stents in other kinds of models [22]. In contrast to the Neuroform device, which was designed to maintain coils in an aneurysm cavity, the novel endovascular devices D1 and D2 were specifically designed as low-porosity devices to reduce flow in the aneurysm cavity. Our results show that the decrease in porosity from $87 \%$ in the Neuroform to $63 \%$ in D1 or D2 leads to a substantial decrease in flow and vorticity (Table 3 and Figure 6).

Although porosity is the major factor affecting intraaneurysmal flow reduction, we also found that the two novel devices D1 and D2, which have exactly the same porosity $(63 \%)$, provoked quite different flow reduction rates, especially in inertia-driven flow models (Table 3 and Figure 6). These results indicate that the stent design itself may be a parameter of interest when it comes to flow efficiency.

\section{Flow Diverter Effects on Velocity and Vorticity}

All devices affected mean flow and vorticity in a similar manner. Despite qualitative differences in the nature of the intraaneurysmal flow field (Figures 3 to 5), velocity and vorticity magnitudes were reduced proportionally when porosity was reduced (Figure 6). Hence, both mean velocity and RMS of vorticity can equally well represent the effects of flow diverters. Wall shear stress (WSS) is an important hemodynamic parameter derived from the flow field, often described to be a major indicator of aneurysmal rupture [23]. However, in this study, WSS could not be assessed due to higher measurement error on velocity vectors near or at the wall and to the small displacements of the model walls under pulsating flow conditions.

\section{Shear-Driven versus Inertia-Driven Flow}

Velocity and vorticity values were generally two to three times higher in the inertia-driven flow model than in the shear-driven flow model. The results obtained underline the fact that flow diversion depends as much on the individual vascular geometry and local flow conditions as on specific diverter design. Predicting the efficiency of a specific flow-diverting device in reducing intraaneurysmal flow cannot be done simply by evaluating the device porosity and strut design. One needs to include local arterial geometry and flow conditions. Ideally, the assessment of an optimal flow-diverting device should be done on a per-patient basis, where the patient-specific geometry and local hemo- dynamics are taken into account. This renders, however, the analysis complicated and cumbersome for clinical applications.

\section{Effects of Amplitude and Pulsatility of Flow}

The results have shown that flow reduction under pulsating and steady flow at comparable mean flows is overall quite similar for both shear-driven and inertia-driven flows and for all tested devices (Table 3 ). The results also show that, under steady flow conditions, flow reduction is inversely proportional to flow rate. Under pulsatile flow conditions, the inserted flow diverters acted as a low-pass filter, reducing the velocity and vorticity absolute values but also reducing the difference between the highest and lowest value during the cardiac cycle. As a result, filtered-flow waveforms inside the aneurysm cavity creating more diffuse and homogeneous flow patterns are obtained.

\section{Limitations}

Limitations of this study are mainly inherent to the adopted experimental methodology. For instance, the measurements were made in the mid-transectional aneurysmal plane, however, as the laser beam had a nonnegligible thickness, particles located close but out of this plane were illuminated and thus counted in the measurements. Light reflection caused difficulties in measuring velocity in the vicinity of device struts. This effect was observed especially in Neuroform stents and to thwart this limitation, the laser intensity was reduced causing small shadow zones, where no measurement could be done. This problem was not observed on devices D1, D2, and D1 + D2.

\section{Clinical Application}

The stent-in-stent combination of D1 and D2 led to severe aneurysmal flow reduction and is likely a good therapeutic candidate for stabilizing aneurysms by inducing thrombus formation. At the moment, however, there exists no defined flow, vorticity or WSS reduction threshold to be reached to qualify a flow diverter as clinically efficient. In consequence, it might be unnecessary for a device to reach a $90 \%$ reduction. Lowering the device porosity could seem a capable means to facilitate aneurysm thrombus formation; however, thrombus formation is a complex system event that might happen under certain circumstances that might not only be related to the flow reduction. In-stent clot 
formation risks may also be raised. Moreover, the cerebrovasculature has many side branches with a diameter of $\leq 200 \mu \mathrm{m}$ and an unfortunate placement of a stent strut or wire against such branch may block flow into the branch.

Due to the complexity of the procedure, the exact position of an intracranial flow-diverting device cannot be fully determined in advance and the stent positioning approximation can reach $1.5 \mathrm{~mm}$. Some intracranial stents have a large open-cell design with variable space between the struts when placed in curved segments. It is therefore hard to predict the efficiency of the device in covering part of the aneurysm neck, as this is strongly dependent on the relative placement. The development of endovascular devices with the same porosity but with smaller wire diameter and smaller window sizes may reduce this dependency as well as the potential side branches' occlusion risks.

\section{Conclusion and Outlook}

In the mid-1980s, cerebral aneurysms were treated by filling the cavity with a balloon; in the 1990s, coils were used to fill in the aneurysm cavity and slow down the blood reducing the shear level and provoking a thrombus. Currently, stents are used to maintain coils inside the aneurysm. It is thought that stents alone would be able to treat such disease by acting more as a "flow diverter" rather than as a "mechanical support for coils" $[8,9]$. Indeed, stents may aspire at three potential purposes: the aneurysmal/arterial circulation disconnection, the aneurysmal in-jet redirection, and the establishment of a scaffold useful for vessel repair. Intense research and development efforts are under way for the design of stents, which would divert flow and stabilize aneurysms in an optimal fashion. Our results lead us to suggest that stents with low porosity might be good candidates for reducing aneurysmal flow and stabilizing the aneurysm, however, their effectiveness is not dependent solely on porosity but also on local geometry and local hemodynamic conditions.

\section{Acknowledgments}

This work was partially supported by the Egon Naef Foundation (http://www.fondation-naef.com) for in vitro research, the Swiss National Research Foundation (grant number 3252B0-105735/1).

This work was generated in the framework of the @neurIST Project, which is cofinanced by the European Commission through the contract no. IST-027703.

The authors also wish to warmly thank all technicians from the Hydraulic Machines Laboratory (http://www.lmh.epfl.ch, Lausanne, Switzerland).

\section{Conflict of Interest Statement}

The authors declare that there is no actual or potential conflict of interest in relation to this article.

\section{References}

1. Wiebers D0, Whisnant JP, Huston J 3rd, Meissner I, Brown RD Jr, Piepgras DG, Forbes GS, Thielen K, Nichols D, O'Fallon W M, Peacock J, Jaeger L, Kassell NF, Kongable-Beckman GL, Torner JC. Unruptured intracranial aneurysms: natural history, clinical outcome, and risks of surgical and endovascular treatment. Lancet 2003:362:103-10.

2. van der Schaaf I, Algra A, Wermer M, Molyneux A, Clarke M, van Gijn J, Rinkel G. Endovascular coiling versus neurosurgical clipping for patients with aneurysmal subarachnoid haemorrhage. Cochrane Database Syst Rev 2005;4:CD003085.

3. Duerig TW, Wholey M. A comparison of balloon- and self-expanding stents. Minim Invasive Ther Allied Technol 2002;11:173-8.

4. Kim SH, Choi CH, Lee TH, Lee SW. Endovascular treatment by using double stent method for ruptured vertebral artery dissecting aneurysms. J Korean Neurosurg Soc 2005;38:132-5.

5. Ahn JY, Han IB, Kim TG, Yoon PH, Lee YJ, Lee BH, Seo SH, Kim DI, Hong CK, Joo JY. Endovascular treatment of intracranial vertebral artery dissections with stent placement or stent-assisted coiling. AJNR Am J Neuroradiol 2006;27:1514-20.

6. Benndorf G, Herbon U, Sollmann WP, Campi A. Treatment of a ruptured dissecting vertebral artery aneurysm with double stent placement: case report. AJNR Am J Neuroradiol 2001;22:1844-8.

7. Zenteno MA, Murillo-Bonilla LM, Guinto G, Gomez CR, Martinez SR, Higuera-Calleja J, Lee A, Gomez-Llata S. Sole stenting bypass for the treatment of vertebral artery aneurysms: technical case report. Neurosurgery 2005;57:Suppl:E208, discussion E208.

8. Kallmes DF, Ding YH, Dai D, Kadirvel R, Lewis DA, Cloft HJ. A new endoluminal, flow-disrupting device for treatment of saccular aneurysms. Stroke 2007:38:2346-52.

9. Ahlhelm F, Roth C, Kaufmann R, Schulte-Altedorneburg G, Romeike BF, Reith W. Treatment of wide-necked intracranial aneurysms with a novel self-expanding two-zonal endovascular stent device. Neuroradiology 2007;49:1023-8.

10. Vanninen $\mathrm{R}$, Manninen $\mathrm{H}$, Ronkainen A. Broad-based intracranial aneurysms: thrombosis induced by stent placement. AJNR Am J Neuroradiol 2003;24:263-6.

11. Lieber BB, Stancampiano AP, Wakhloo AK. Alteration of hemodynamics in aneurysm models by stenting: influence of stent porosity. Ann Biomed Eng 1997;25:460-9.

12. Meng H, Wang Z, Kim M, Ecker RD, Hopkins LN. Saccular aneurysms on straight and curved vessels are subject to different hemodynamics: implications of intravascular stenting. AJNR Am J Neuroradiol 2006:27:1861-5.

13. Kim C, Cervos-Navarro J, Patzold C, Tokuriki Y, Takebe Y, Hori K. In vivo study of flow pattern at human carotid bifurcation with regard to aneurysm development. Acta Neurochir (Wien) 1992;115:112-7.

14. Nakatani $\mathrm{H}$, Hashimoto $\mathrm{N}$, Kikuchi $\mathrm{H}$, Yamaguchi $\mathrm{S}$, Niimi $\mathrm{H}$. In vivo flow visualization of induced saccular cerebral aneurysms in rats. Acta Neurochir (Wien) 1993;122:244-9.

15. Rhee K, Han MH, Cha SH. Changes of flow characteristics by stenting in aneurysm models: influence of aneurysm geometry and stent porosity. Ann Biomed Eng 2002;30:894-904.

16. Barath K, Cassot F, Fasel JH, Ohta M, Rufenacht DA. Influence of stent properties on the alteration of cerebral intra-aneurysmal haemodynamics: flow quantification in elastic sidewall aneurysm models. Neurol Res 2005;27:Suppl 1:S120-8.

17. Barath K, Cassot F, Rufenacht DA, Fasel JH. Anatomically shaped internal carotid artery aneurysm in vitro model for flow analysis to evaluate stent effect. AJNR Am J Neuroradiol 2004:25:1750-9. 
18. Ohta M, Fujimura N, Augsburger L, Barath K, Yilmaz H, Abdo G, Lovblad K0, Rufenacht DA. Subtracted vortex centers path line method with cinematic angiography for measurement of flow speed in cerebral aneurysms. Neurol Res 2008;30:251-5.

19. Lieber BB, Livescu V, Hopkins LN, Wakhloo AK. Particle image velocimetry assessment of stent design influence on intra-aneurysmal flow. Ann Biomed Eng 2002;30:768-77.

20. Canton G, Levy DI, Lasheras JC, Nelson PK. Flow changes caused by the sequential placement of stents across the neck of sidewall cerebral aneurysms. J Neurosurg 2005;103:891-902.

21. Yu SC, Zhao JB. A steady flow analysis on the stented and non-stented sidewall aneurysm models. Med Eng Phys 1999;21:133-41.

22. Canton G, Levy DI, Lasheras JC. Hemodynamic changes due to stent placement in bifurcating intracranial aneurysms. J Neurosurg 2005; 103:146-55.
23. Shojima M, Oshima M, Takagi K, Torii R, Hayakawa M, Katada K, Morita A, Kirino T. Magnitude and role of wall shear stress on cerebral aneurysm: computational fluid dynamic study of 20 middle cerebral artery aneurysms. Stroke 2004;35:2500-5.

\section{Address for Correspondence}

Luca Augsburger

Hemodynamic and Cardiovascular Technology Laboratory Life Science

École Polytechnique Fédérale de Lausanne

1015 Lausanne

Switzerland

Phone (+41/22) 37-27045, Fax -95402

e-mail: luca.augsburger@epfl.ch 